\title{
Microalbuminuria in non-insulin-dependent (type 2) Nigerian diabetics: relation to glycaemic control, blood pressure and retinopathy
}

\author{
R.T. Erasmus, G. Oyeyinka and A. Arije ${ }^{1}$ \\ Department of Chemical Pathology \& Immunology and ${ }^{1}$ Department of Medicine, University of Ilorin, \\ Ilorin, Nigeria
}

\begin{abstract}
Summary: Twenty-four hour urinary albumin concentrations were measured in 113 (mean age 51.1 years) non-insulin-dependent (NIDDM) Nigerian diabetics (50 males, 63 females). A high prevalence of microalbuminuria ( $\geqslant 30 \mathrm{mg} / 24$ hour) was observed in male (54\%) as well as female diabetics (59\%). Microalbuminuria was also observed in a high proportion of diabetics $(52 \%)$ with a short duration $(<5$ years) of disease. Elevated blood pressure and retinopathy were present in $41 \%$ and $16 \%$ of patients respectively. Among the 49 patients with normoalbuminuria $(<30 \mathrm{mg} / 24$ hour), six $(12 \%)$ had retinopathy compared with $12(18 \%)$ in the microalbuminuria group. Diastolic blood pressure levels were significantly higher $(P<0.01)$ in male diabetics with retinopathy but this was not associated with higher albuminuria. Urinary albumin concentrations were not influenced by elevated blood pressure. There were no significant differences in age, duration of diabetes, blood pressure or serum creatinine between diabetics with and without microalbuminuria. These results suggest that though there is a high prevalence of microalbuminuria amongst NIDDM Nigerian diabetics it may not predict retinopathy and occurs independently of either glycaemic control or elevated blood pressure levels.
\end{abstract}

\section{Introduction}

Renal impairment is common in non-insulin-dependent diabetes mellitus (NIDDM), and proteinuria has been shown to predict early mortality. ${ }^{1-3}$ Proteinuria usually refers to 'Albustix positive' proteinuria corresponding to an albumin concentration of at least $300 \mathrm{mg} / \mathrm{l}$. Urinary albumin excretion (UAE) that exceeds normal values but falls short of clinical proteinuria has been termed microalbuminuria. There is evidence to suggest that microalbuminuria may predict clinical proteinuria and mortality in insulin- and non-insulindependent diabetics. ${ }^{2,4,5}$

Diabetes mellitus is increasingly being seen in Nigerians, ${ }^{6}$ and previous studies have reported a high prevalence of clinical proteinuria in Nigerian diabetics. ${ }^{7,8}$ The aim of the present study was to identify non-insulin-dependent Nigerian diabetics with microalbuminuria, and examine the relationship between elevated albumin levels and known risk factors such as blood pressure, glycaemic control and retinopathy.

Correspondence: R.T. Erasmus, M.B., B.S., F.M.C. Path., F.A.C.B., Department of Pathology, Faculty of Medicine, University of Papua New Guinea, PO Box 5623, Boroko, Papua New Guinea.

Accepted: 4 November 1991

\section{Materials and methods}

All non-insulin-dependent diabetics attending the diabetic clinic were eligible for the study if they satisfied the following criteria: (a) absence of persistent proteinuria or macroproteinuria (Albustix positive); (b) plasma creatinine levels not exceeding $130 \mu \mathrm{mol} / \mathrm{l}$; (c) absence of concomitant renal disease or urinary tract infection; and (d) fasting plasma glucose levels $<13 \mathrm{mmol} / \mathrm{l}$.

One hundred and seventy non-insulin-dependent diabetics satisfied the above criteria and were asked to participate in the study. Fifty patients declined to participate and complete records were not available on seven patients leaving 113 patients for the present study.

\section{Procedures}

Patients were supplied with 3 litre containers for 24 hour urine collection. The patients were verbally instructed in the principles of collecting a 24 hour urine and then supplied with written instructions. A mid-stream urine sample was obtained to exclude urinary infection following the urine collection. A $10 \mathrm{ml}$ blood sample was collected from each patient (fasting) for plasma glucose, creatinine and electrolytes. The weight and height for each patient 
was recorded. Body mass index (BMI) was calculated as weight/height ${ }^{2}$. Blood pressure was measured after 10 minutes in the supine posture by the same observer using a standard mercury sphygmomanometer and the Korotkoff phase $\mathrm{V}$ was used to define the diastolic end point. Ophthalmoscopy through dilated pupils ( $1 \%$ homatropine) was carried out within one week of urine collection. Diabetic retinopathy was identified as previously described. $^{?}$

\section{Glycaemic control}

Glycaemic control in each patient was calculated by taking the means of fasting plasma glucose values over 6 months preceding the fundoscopic examination. Poor 'glycaemic control' was arbitrarily defined as fasting plasma glucose (FPG) $>10 \mathrm{mmol} / \mathrm{l}$.

\section{Diagnostic criteria}

Normal blood pressure was considered to be a systolic reading $<140 \mathrm{mmHg}$ and a diastolic reading $<90 \mathrm{mmHg}$. Microalbuminuria was defined as UAE of more than $20 \mu \mathrm{g} / \mathrm{min}(30 \mathrm{mg} / 24$ hour $)$ and less than $200 \mu \mathrm{g} / \mathrm{min}$ ( $300 \mathrm{mg} / 24$ hour). ${ }^{2,5}$ The normal range for urinary albumin concentration in our laboratory was $6-25 \mathrm{mg} / 24$ hour (40 males, 35 females, mean age 38 years, range $21-50$ years). Normoalbuminuria was defined as UAE of less than or equal to $20 \mu \mathrm{g} / \mathrm{min}(30 \mathrm{mg} / 24$ hour). The current age was defined as that at the time of examination. The duration of diabetes was the time period between the age at diagnosis and the current age.

\section{Laboratory analysis}

Urinary albumin concentration was assayed by immunodiffusion. ${ }^{9}$ Plasma glucose concentrations were measured by the glucose oxidase method and creatinine by the Jaffe reaction.

\section{Statistical analysis}

All statistical analysis was carried out on a Prime computer using the BMDP85 statistical package. Urinary albumin concentrations were logarithmically transformed before analysis and are expressed as geometric means. Differences between variables were assessed by one-way analysis of variance or chi-square tests as appropriate. Relationships between variables were calculated with Pearson's product moment coefficient of correlation. Multiple regression analysis was performed using log albumin concentration as the dependent variable, data only being subjected to a stepwise selection procedure if significant associations were observed. Differences were considered statistically significant if $\boldsymbol{P}$ values were less than 0.05 .

\section{Results}

Details of the characteristics of the diabetic subjects are shown in Table I. Females had a higher BMI than male diabetics $(P<0.002)$, but both sexes were similar with respect to age, duration of disease, glycaemic control and blood pressure measurements. There were $18(16 \%)$ diabetics with retinopathy (five males and 13 females).

Microalbuminuria was detected in 57\% (27

Table I Characteristics of non-insulin-dependent diabetic patients (mean \pm SEM (range))

\begin{tabular}{lcc}
\hline & Male & Female \\
\hline Number & 50 & 63 \\
Age (years) & $51 \pm 1.0$ & $51 \pm 1.1$ \\
& $(35-65)$ & $(30-65)$ \\
Duration (years) & $4.8 \pm 0.6$ & $5.4 \pm 0.5$ \\
& $(0.2-25)$ & $(0.2-17)$ \\
Body mass index (BMI) & $24 \pm 0.5$ & $27 \pm 0.6^{*}$ \\
Fasting plasma glucose (mmol/l) & $(18-35)$ & $(17-40)$ \\
Plasma creatinine ( $\mu$ mol/l) & $9 \pm 0.3$ & $(5-0.3$ \\
Systolic blood pressure (mmHg) & $(5-13)$ & $91 \pm 2$ \\
& $110 \pm 2$ & $(62-130)$ \\
Diastolic blood pressure (mmHg) & $(66-130)$ & $135 \pm 2$ \\
& $137 \pm 2$ & $(100-190)$ \\
Number of patients with: & $(110-170)$ & $87 \pm 2$ \\
retinopathy & $90 \pm 1$ & $(60-110)$ \\
hypertension & $(70-110)$ & 13 \\
\hline
\end{tabular}

${ }^{*} P<0.002$ 
males and 37 females) and elevated blood pressure in $41 \%$ (19 males and 27 females) of the patients (Table II). There were no significant differences in age, duration of diabetes, glycaemic control, blood pressure or creatinine between diabetics with and without microalbuminuria. The prevalence of microalbuminuria was similar in male and female diabetics (Table III). Normotensive and hypertensive diabetics also demonstrated similar prevalence rates of microalbuminuria. Microalbuminuria occurred at all known duration of diabetes including patients shortly after diagnosis and was not affected by the degree of glycaemic control (Table III), the prevalence of microalbuminuria not being significantly different in either the 'good' or 'poor' control groups, respectively.

Among the 49 patients with normoalbuminuria, six $(12 \%)$ had retinopathy compared with $18 \%$ $(12 / 64)$ in the microalbuminuria group. Diastolic blood pressure levels were significantly higher $(P<0.01)$ in male diabetics with retinopathy but this was not associated with higher albuminuria (Table IV).

No significant correlations were observed be- $\stackrel{\mathbb{Q}}{\complement}$ tween urinary albumin excretion (UAE) and age, $\stackrel{\hookrightarrow}{.}$ BMI, systolic or diastolic blood pressure, plasma $\underset{\vec{S}}{\vec{S}}$ glucose concentration or duration of diabetes on $\overrightarrow{0}$ univariate analysis. Using multiple regression ana- $\frac{\bar{O}}{0}$ lysis with $\log _{10}$ albumin concentration as the depen- $\frac{\bar{\omega}}{\sigma}$ dent variable, none of the regression coefficients of $\bar{D}$ independent variables were significant.

\section{Discussion}

This study has demonstrated a high prevalence of microalbuminuria (57\%) in non-insulin-dependent Nigerian diabetics. Microalbuminuria was also observed in a high proportion of diabetics with a short duration ( $<5$ years) of disease (Table III). This is unlikely to be attributed to the increased of albumin excretion seen in uncontrolled diabetics $\mathscr{\Phi}_{\infty}$

Table II Relationship of duration, blood pressure, retinopathy and other variables to albumin excretion in male and female diabetics

\begin{tabular}{|c|c|c|c|c|c|}
\hline & & & & & \\
\hline & $<30 \mathrm{mg} / 24$ hour & $>30 \mathrm{mg} / 24$ hour & $<30 \mathrm{mg} / 24$ hour & $>30 \mathrm{mg} / 24$ hour & 은 \\
\hline Number & 23 & 27 & 26 & 37 & 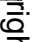 \\
\hline Age (years) & $51(1)$ & $50(1)$ & $50(2)$ & $52(1)$ & $\underset{\rightleftharpoons}{\rightleftharpoons}$ \\
\hline Duration (years) & $4.8(1.2)$ & $4.7(0.2)$ & $4.6(0.8)$ & $6.0(0.7)$ & \\
\hline BMI & $23.0(0.6)$ & $25(0.7)$ & $27(1.0)$ & $26(0.8)$ & \\
\hline Systolic BP (mmHg) & $139(3.0)$ & $135(3)$ & $134(4)$ & $136(3)$ & \\
\hline Diastolic BP $(\mathrm{mmHg})$ & $90(2)$ & $90(2)$ & $84(2)$ & $89(2)$ & \\
\hline Glucose $(\mathrm{mmol} / \mathrm{l})$ & $8.4(0.4)$ & $9.4(0.5)$ & $8.7(0.5)$ & $9.4(0.4)$ & \\
\hline Creatinine $(\mu \mathrm{mol} / \mathrm{l})$ & $114(3.0)$ & $106(3.0)$ & $89(4)$ & $93(3)$ & \\
\hline Retinopathy (\%) & $9(2)$ & $11(3)$ & $15(4)$ & 24(9) & \\
\hline
\end{tabular}

Table III Proportion of 113 Nigerian diabetics with microalbuminuria ( $>30 \mathrm{mg} / 24$ hour) within categories of other variables

\begin{tabular}{|c|c|c|c|c|}
\hline & Variable & $n$ & $\%$ & Significance \\
\hline \multirow[t]{3}{*}{ (a) } & Sex & & & \\
\hline & Males & 50 & $54(27)$ & N.S. \\
\hline & Females & 63 & $59(37)$ & \\
\hline \multirow[t]{3}{*}{ (b) } & Elevated blood pressure & & & \\
\hline & No & 67 & $51(38)$ & \\
\hline & Yes & 46 & $57(26)$ & N.S. \\
\hline \multirow[t]{3}{*}{ (c) } & Fasting glucose groups & & & \\
\hline & $<10 \mathrm{mmol} / \mathrm{l}$ & 76 & $53(40)$ & \\
\hline & $>10 \mathrm{mmol} / \mathrm{l}$ & 37 & $65(24)$ & N.S. \\
\hline \multirow[t]{3}{*}{ (d) } & Duration of diabetes & & & \\
\hline & $<5$ years & 66 & $52(34)$ & \\
\hline & $>5$ years & 47 & $64(30)$ & N.S. \\
\hline \multirow{2}{*}{ (e) } & $\begin{array}{l}\text { Retinopathy } \\
\text { No }\end{array}$ & & & NS \\
\hline & Yes & 18 & $67(12)$ & N.S. \\
\hline
\end{tabular}

N.S. = not significant . 
Table IV Relationship of blood pressure, albumin excretion and other variables in NIDDM subjects with retinopathy

\begin{tabular}{|c|c|c|c|c|}
\hline \multirow[b]{2}{*}{ Variable } & \multicolumn{2}{|c|}{ Males } & \multicolumn{2}{|c|}{ Females } \\
\hline & $\begin{array}{l}\text { Without } \\
\text { retinopathy }\end{array}$ & $\begin{array}{c}\text { With } \\
\text { retinopathy }\end{array}$ & $\begin{array}{l}\text { Without } \\
\text { retinopathy }\end{array}$ & $\begin{array}{c}\text { With } \\
\text { retinopathy }\end{array}$ \\
\hline Number & 45 & 5 & 50 & 13 \\
\hline Age (years) & $51(1)$ & $51(1)$ & $51(1)$ & $53(2)$ \\
\hline Duration (years) & $5(1)$ & $4(2)$ & $5(1)$ & $5(1)$ \\
\hline Systolic BP & $135(15)$ & $144(3)$ & $134(3)$ & $139(5)$ \\
\hline Diastolic BP & $88(1)$ & $100(3)^{*}$ & $86(2)$ & $90(3)$ \\
\hline Albumin $(\mathrm{mg} / \mathrm{l}) \dagger$ & $35(2)$ & 43(3) & $31(3)$ & 48(2) \\
\hline
\end{tabular}

${ }^{*} P<0.01 ; \nmid$ albumin values expressed as geometric means.

since patients with poor glycaemic control were excluded. Even if the possibility of overestimation is considered, the prevalence of microalbuminuria in Nigerian diabetics is much higher than in previous studies. ${ }^{10-12}$

Though several studies have reported a significant correlation between UAE, proteinuria and glycaemic control, ${ }^{1,13-17}$ we observed no association between microalbuminuria and glycaemic control. One study found no association between microalbuminuria and level of glycaemia ${ }^{18}$ and another found the association in females only. ${ }^{19}$

Our study showed similar blood pressure levels in normoalbuminuric and microalbuminuric diabetics (Tables II and III). Furthermore, no significant correlations were observed between either systolic or diastolic blood pressure levels and UAE. These results are in contrast to other studies which have emphasized the importance of the association between UAE and elevated blood pressure.$^{13-15,18,19}$ Microalbuminuria occurred at all known durations of diabetes and our data suggest that abnormal albumin excretion may be detectable shortly after diagnosis. The duration of diabetes was not a significant correlate of microalbuminuria in Nigerian diabetics despite the observation of poorer control in diabetics of longer duration. These findings are similar to those reported in Nauruan diabetics ${ }^{13}$ and in diabetics from Papua New Guinea. ${ }^{20}$ Schmitz and Vaeth ${ }^{15}$ also observed no significant association between UAE and duration of NIDDM. However, Marshall and Alberti ${ }^{21}$ found duration of disease to be a strong predictor of microalbuminuria and others ${ }^{1,17}$ found the prevalence of proteinuria to increase with duration. These conflicting observations may probably have occurred because of the difficulty in dating the onset of NIDDM. In many African countries diabetes goes undetected for long periods of time and it is not uncommon for newly diagnosed diabetics to present with established complications. $^{6,22}$

Our findings suggest that NIDDM patients with abnormal albumin excretion were not at risk of developing retinopathy. Even though diastolic blood pressure was higher in male diabetics with retinopathy, it was not associated with higher albuminuria (Table IV). These observations are in contrast to reports from several centres which have linked retinopathy to increased urinary albumin excretion in patients with either insulin or noninsulin-dependent diabetes..$^{21,23-25}$ Though the association of retinopathy and Albustix-positive proteinuria has long been recognized ${ }^{25}$ it is not frequently observed in the Nigerian diabetic. ${ }^{7}$

The high prevalence of microalbuminuria observed in this study and its lack of association with known risk factors was unexpected. This may be due to variability in albumin excretion, collection methods, and physical activity. It is not uncommon for diabetic patients in Nigeria to walk several kilometres to the hospital. Furthermore, since this was a cross-sectional study, it may not thus truly represent preceding events in the development of diabetic complications. Ethnic factors may also have contributed to the high rate of microalbuminuria. For example, Collins et al..$^{13}$ found a high frequency of albuminuria in Nauruans and another study found ethnicity to be an independent determinant of microalbuminuria in a group of Mexican Americans and non-Hispanic Whites with NIDDM.$^{18}$ Similarly, a high proportion of British Indians with NIDDM were found to have elevated urinary albumin excretion compared with a group of white diabetic patients. ${ }^{26}$ More recently we have also reported similar observations in diabetics from Papua New Guinea. ${ }^{20}$

Several studies have shown microalbuminuria to be a strong predictor of clinical nephropathy and early mortality in NIDDM. Two separate studies from Africa have reported a high prevalence of clinical nephropathy despite a short duration of disease ${ }^{27-28}$ However the results of this study need to be interpreted with caution in view of the intraindividual variability in the excretion of albumin. Further studies are required to confirm our observations. 


\section{References}

1. Fabre, J., Balant, L., Dayer, P., Fox, H.M. \& Vernet, A.T The kidney in maturity onset diabetes mellitus: a clinical study of 510 patients. Kidney Int 1983, 21: 730-738.

2. Mogensen, C.E. Microalbuminuria predicts clinical proteinuria and early mortality in maturity onset diabetes. $N$ Engl J Med 1984, 310: 356-360.

3. Nelson, R.G., Pettitt, D.J., Carraher, M.J., Baird, H.R. \& Knowler, W.C. Effect of proteinuria on mortality in NIDDM. Diabetes 1988, 37: 1499-1450.

4. Mogensen, C.E. Prediction of clinical diabetic nephropathy in IDDM patients. Alternatives to microalbuminuria? Diabetes 1990, 39: 761-767.

5. Jarrett, R.J., Viberti, G.C., Argyropoulos, A. et al. Microalbuminuria predicts mortality in non insulin dependent diabetes. Diabetic Med 1984, 1: 17-19.

6. Erasmus, R.T., Fakeye, T., Olukoga, A.O. et al. Prevalence of diabetes mellitus in a Nigerian population. Trans $R$ Soc Med Hyg 1989, 83: 417-418.

7. Erasmus, R.T., Alanamu, R.A., Bojuwoye, B., Oluboyo, P.\& Arije, A. Diabetic retinopathy in Nigerians: relation to duration of diabetes, type of treatment and degree of control. E Afr Med J 1989, 4: 258-254.

8. Arije, A., Erasmus, R.T. \& Akimsola, A. Renal function in adult Nigerian diabetics. Ann Clin Biochem 1987, (Suppl. 2): 238.

9. Fafey, J.H. \& McKelvey, E.M. Quantitative determination of serum immunoglobulins in antibody agar plates. $J$ Immunol 1965, 94: 84-90.

10. Mogensen, C.E. A complete screening of urinary albumin concentration in an unselected diabetic outpatient clinic population. Diabetic Nephropathy 1984, 3: 135-139.

11. Damsgaard, E.M. \& Mogensen, C.E. Microalbuminuria in elderly hyperglycaemic patients and controls. Diabetic Med 1986, 3: 430-435.

12. Marre, M. \& Passa, P. Prevalence of microalbuminuria in the diabetic clinic. In: Mogensen, C.E. (ed) The Kidney and Hypertension in Diabetes. Boston, Martinus Nijhoff, 1988, pp. $51-58$.

13. Collins, V.R., Dowse, G.K., Finch, C.F., Zimmet, P.Z. \& Linnane, A.W. Prevalence and risk factors for micro- and macroalbuminuria in diabetic subjects and entire population of Nauru. Diabetes 1989, 38: 1602-1610.

14. Gatling, W., Mullee, M.A., Knight, C. \& Hill, R.D. Microalbuminuria in diabetes: relationships between urinary albumin excretion and diabetes related variables. Diabetic Med 1988, 5: $348-351$.

15. Schmitz, A. \& Vaeth, M. Microalbuminuria: a major risk factor in non insulin dependent diabetes: a 10 year followup study of 503 patients. Diabetic Med 1988, 5: 126-134.
16. Ballard, D.J., Humphrey, L.L., Melton, L.J., III et al. $\varrho$ Epidemiology of persistent proteinuria in type II diabetes $\subseteq$ mellitus: population based study in Rochester, Minnesota. Diabetes 1988, 37: 405-412.

17. West, K.M., Erdreich, L.J. \& Stober, J.A. A detailed study of risk factors for retinopathy and nephropathy in diabetes. Diabetes 1980, 29: 501-508.

18. Haffner, S.M., Stern, M.P. \& Mitchell, B.D. Increased $\frac{\mathscr{D}}{\widehat{D}}$ prevalence of microalbuminuria in Mexican Americans, a $\unrhd$ high risk population for non insulin dependent diabetes mellitus. Proceedings of the 13th International Diabetes Federation Congress 1988, Hobart, Tasmania.

19. Mattock, M.B., Keen, H., Viberti, G.C., Murrellis, T.J. \& Jackson, R.G. Cross-sectional associations with urinary $\vec{\omega}$ albumin excretion rate in type II patients. Proceedings of the $\vec{D}$ 13th International Diabetes Federation Congress 1988, Hobart, Tasmania.

20. Sinha, A.K., Erasmus, R.T. \& Mogia, N. Blood pressure, serum creatinine and microalbuminuria in non insulin depen- $\infty$ dent Melanesian diabetics. Diabetes 1991, 40 (Suppl I): 381A. $\infty$

21. Marshall, S.M. \& Alberti, K.G.M.M. Comparison of the prevalence and associated features of abnormal albumin excretion in insulin dependent and non-insulin dependent diabetes. $Q J$ Med 1989, 261: 61-71.

22. Ahren, B. \& Corrigan, C.B. Prevalence of diabetes mellitus in $\frac{\mathrm{O}}{\mathrm{J}}$ north-western Tanzania. Diabetologia 1984, 26: 333-336.

23. Parving, H.-H., Hommel, E., Mathiesen, E. et al. Prevalence $D$ of microalbuminuria, arterial hypertension, retinopathy and neuropathy in patients with insulin-dependent diabetes. $\mathrm{Br}$ Med J 1988, 296: 156-160.

24. Barnett, A.H., Dallinger, K., Jennings, P., Fletcher, J. $\& \vec{\theta}$ Odugbesan, $O$. Microalbuminuria and diabetic retinopath Lancet 1986, i: 53-54.

25. Ireland, J.T., Viberti, C.G. \& Watkin, P.J. The kidney and renal tract. In: Keen, J. and Jarrett, J.R. (eds) Complications of Diabetes. Edward Arnold, London, 1982, pp. 137-178.

26. Allawi, J., Rao, P.V., Gilbert, R. et al. Microalbuminuria in $\bar{O}$ non insulin dependent diabetics: its prevalence in Indian compared with Europid patients. Br Med J 1988, 296: 462-464.

27. Bella, A.F., Famuyiwa, O., Adenaike, F.A., Osotimehin, B.\& $\overrightarrow{\overrightarrow{0}}$ Adetuyibi, A. A clinical study of diabetic nephropathy in 3 Nigerian diabetic patients. Nig Med J 1988, 4: 265-268.

28. Lester, F.T. The clinical pattern of diabetes mellitus in Ethiopians. Diabetes Care 1984, 7: 6-11. 